\title{
Trocas gasosas e estresse oxidativo em plantas de algodoeiro supridas com silício e infectadas por Ramularia areola
}

\author{
Carmen Rosa da Silva Curvêlo ( $\left.{ }^{1 *}\right)$; Fabrício Ávila Rodrigues ( $\left.{ }^{2}\right)$; Lucas Felisberto Pereira (3); \\ Leandro Castro Silva ( $\left.{ }^{2}\right)$; Fábio Murilo DaMatta (3); Paulo Geraldo Berger (') \\ (') Universidade Federal de Viçosa (UFV), Departamento de Fitotecnia, Av. Peter Henry Rolfs, s/n, 36570-000 Viçosa (MG), Brasil. \\ (2) UFV, Departamento de Fitopatologia, 36570-000 Viçosa (MG), Brasil. \\ (3) UFV, Departamento de Biologia Vegetal, 36570-000 Viçosa (MG), Brasil. \\ $\left({ }^{*}\right)$ Autor correspondente: carmencurvelo@yahoo.com.br
}

Recebido: 28/abr./2013; Aceito: 10/nov./2013

\begin{abstract}
Resumo
Considerando o efeito positivo do silício (Si) na melhoria do desempenho fisiológico de várias espécies de plantas quando infectadas por patógenos, este trabalho teve como meta investigar o efeito desse elemento na capacidade fotossintética e no metabolismo antioxidativo de plantas dos cultivares de algodoeiro NuOpal e BRS Buriti, supridas ou não com Si, durante o processo infeccioso de Ramularia areola. A infecção por $R$. areola afetou negativamente a taxa líquida de fixação do $\mathrm{CO}_{2}(A)$, a condutância estomática $\left(g_{s}\right)$, a transpiração e a razão entre concentração interna e ambiente de $\mathrm{CO}_{2}$ nas plantas dos cultivares NuOpal e BRS Buriti não supridas com Si em relação às plantas supridas com esse elemento. Na presença do Si, houve aumento em $A$ e $g_{s}$ além das concentrações de clorofila $a$, clorofila $b$ e carotenóides nas plantas dos dois cultivares. A concentração foliar de Si aumentou, o que contribuiu para decrescer em 38\% a área abaixo da curva do progresso da mancha de ramulária nas plantas supridas com Si, em relação às plantas não supridas com esse elemento. O fornecimento de Si às plantas de algodoeiro dos dois cultivares aumentou a atividade da dismutase do superóxido (SOD), da peroxidase do ascorbato (APX) e da lipoxigenase (LOX), mas houve redução na atividade da catalase (CAT) e na concentração de peróxido de hidrogênio $\left(\mathrm{H}_{2} \mathrm{O}_{2}\right)$ e de aldeído malônico (MDA), houve ainda uma maior perda de eletrólitos. A atividade da glutationa redutase (GR) foi maior nas plantas do cultivar BRS Buriti supridas com Si, enquanto que nas plantas do cultivar NuOpal houve aumento da atividade da glutationa redutase apenas aos 21 dias após inoculação (dai). Conclui-se que a capacidade fotossintética e o sistema antioxidativo das plantas supridas com Si sofreram menor impacto durante o processo infeccioso de $R$. areola.
\end{abstract}

Palavras-chave: fotossíntese, mancha foliar, nutrição mineral.

\section{Leaf gas exchange and oxidative stress on cotton plants supplied with silicon and infected by Ramularia areola}

\begin{abstract}
Considering the positive effect of silicon (Si) in improving the physiological performance of several plant species when infected by pathogens, this study investigated the effect of this element in the photosynthetic capacity and on the antioxidant metabolism of cotton plants from cultivars BRS NuOpal and Buriti, supplied or not with Si, during the infectious process of Ramularia areola. The infection by $R$. areola negatively affected the net carbon assimilation rate $(A)$, stomatal conductance to water vapor $\left(g_{s}\right)$, internalto-ambient $\mathrm{CO}_{2}$ concentration ratio and transpiration rate on plants of the two cultivars non-supplied with $\mathrm{Si}$ in comparison to plants supplied with this element. In the presence of $\mathrm{Si}$, there was an increase in $A$ and $g_{\mathrm{s}}$ as well as on the concentrations of chlorophyll $a$, chlorophyll $b$ and carotenoids in plants of both cultivars. The Si supply increased the foliar Si concentration, which contributed to decrease the area under ramularia leaf spot progress curve by $38 \%$ in comparison to plants non-supplied with this element. The Si supply to both cultivars increased the activities of superoxide dismutase and ascorbate peroxidase, but reduced catalase activity. The activity of glutathione reductase was higher on plants from cultivar BRS Buriti supplied with Si, while for the cultivar NuOpal the activity of glutathione reductase increased only after 21 days of inoculation (dai). There was reduction in the concentration of hydrogen peroxide and malondialdehyde until 15 dai and the electrolyte leakage was higher in plants supplied with Si in both cultivars. As compared to non-supplied plants, both cultivars presented increase on lipoxygenase activity when supplied with Si until 12 dai. It was concluded that the photosynthetic capacity and the antioxidative system of plants supplied with Si were less impacted during the infectious process of $R$. areola.
\end{abstract}

Key words: photosynthesis, leaf spot, mineral nutrition. 


\section{INTRODUÇÃO}

A ocorrência de doenças é um dos principais responsáveis pelas grandes perdas que ocorrem na produção do algodão em todas as regiôes produtoras do país (Freire, 2011). A mancha de ramulária, causada pelo fungo Ramularia areola (Atk.), é a principal doença foliar da cultura do algodoeiro (Suassuna e Coutinho, 2011). O fungo infecta as folhas, provocando lesões angulares na superfície foliar e causando desfolha, o que prejudica o rendimento da cultura (SuAssuna e Coutinho, 2011). A principal e a mais eficiente estratégia de manejo para reduzir os sintomas da mancha de ramulária é a aplicação de fungicidas sistêmicos, visto que a maioria dos cultivares de algodão não possui resistência genética a essa doença (Andrade et al., 1999; Suassuna e Coutinho, 2011). Apesar de os cultivares resistentes não estarem disponíveis no mercado, existem diferenças entre eles com relação à susceptibilidade a mancha de ramulária: podemos citar dois cultivares que apresentaram níveis de resistência diferenciados, o cultivar BRS Buriti foi considerado com nível de resistência moderado a muitas doenças, enquanto que o cultivar $\mathrm{NuOpal}$ foi extremamente suscetível a diversos patógenos (ANDRADE et al., 1999).

De acordo com Bolton (2009), os sintomas das doenças podem causar danos às células do mesófilo, às membranas, ao funcionamento da maquinaria enzimática, na abertura e fechamento dos estômatos, afetando a transpiração, o influxo do $\mathrm{CO}_{2}$ e a taxa fotossintética (Berger et al., 2007). Características fotossintéticas tais como as trocas gasosas e a fluorescência da clorofila $a$ têm sido consideradas indicadores úteis do comportamento da atividade do aparelho fotossintético em plantas sob condiçôes de estresse, incluindo os causados pela infecção por patógenos (BERgER et al., 2007).

As plantas dispóem de diferentes estratégias de proteção contra os danos celulares e a morte causada pelo excesso de espécies reativas de oxigênio (ERO) que ocasionam o estresse oxidativo (Asada, 1999). Dentre as principais enzimas antioxidantes envolvidas na detoxificação das ERO estão as $\mathrm{SOD}$, que catalizam a dismutaçáo do $\mathrm{O}_{2}^{-}$a $\mathrm{H}_{2} \mathrm{O}_{2}$ e constituem a primeira linha de defesa contra as ERO (ALscher et al., 2002); as CAT, que convertem o $\mathrm{H}_{2} \mathrm{O}_{2}$ em água e oxigênio (AsADA, 1999) e as enzimas do ciclo ascorbato-glutationa, como as APX, que reduzem o $\mathrm{H}_{2} \mathrm{O}_{2}$ nos plastídeos utilizando o ascorbato como doador de elétrons (YAN et al., 1996). O ascorbato oxidado é, então, reduzido pela glutationa reduzida (GSH) oriunda da glutationa oxidada (GSSG), catalizada pela GR (YAN et al., 1996).

São inúmeros os benefícios proporcionados pelo silício (Si) às plantas sadias e submetidas a diferentes condições de estresse abiótico e/ou biótico (DATNOFF et al., 2007; Epstein, 1994). O fornecimento de $\mathrm{Si}$ às plantas reduz a intensidade de várias doenças (DatNOfF et al., 2007) e essa redução pode ser explicada pela silicificação das células epidérmicas, o que atrasaria a penetração do patógeno (KIm et al., 2002). Entretanto, ainda não é totalmente entendido o envolvimento do Si na fisiologia das plantas superiores, mesmo trazendo inúmeros benefícios a várias espécies de plantas (MA, 2004).

Ainda não se tem nenhum relato na literatura sobre o efeito do Si no patossistema algodão- $R$. areola. A fim de preencher essa lacuna, o presente trabalho tenta reforçar a hipótese de que o fornecimento de Si às plantas de algodoeiro pode trazer benefícios para a maquinaria fotossintética e aumentar a atividade de algumas enzimas antioxidantes, aumentando, assim, a resistência do algodoeiro à mancha de ramulária.

\section{MATERIAL E MÉTODOS}

\section{Preparo da solução nutritiva e crescimento das plantas de algodoeiro}

A solução nutritiva usada neste estudo foi preparada de acordo com Hoagland e ARnon (1950), com algumas modificaçóes, e constituiu-se de: $6,0 \mathrm{mM} \mathrm{KNO} ;$; 1,0 mM $\mathrm{NH}_{4} \mathrm{H}_{2} \mathrm{PO}_{4} ; 2,0 \mathrm{mM} \mathrm{MgSO} .7 \mathrm{H}_{2} \mathrm{O} ; 4,0 \mathrm{mM} \mathrm{Ca}_{2}\left(\mathrm{NO}_{3}\right)_{2}$; $0,3 \mu \mathrm{M} \mathrm{CuSO}_{4} \cdot 5 \mathrm{H}_{2} \mathrm{O} ; 1,3 \mu \mathrm{M} \mathrm{ZnSO}_{4} \cdot 7 \mathrm{H}_{2} \mathrm{O} ; 46 \mu \mathrm{M} \mathrm{H}_{3} \mathrm{BO}_{3}$; $12,6 \mu \mathrm{M} \mathrm{MnCl}_{2} .4 \mathrm{H}_{2} \mathrm{O} ; 0,1 \mu \mathrm{M}\left(\mathrm{NH}_{4}\right)_{6} \mathrm{Mo}_{7} \mathrm{O}_{24} .4 \mathrm{H}_{2} \mathrm{O}$; $45 \mu \mathrm{M} \mathrm{FeSO}_{4} .7 \mathrm{H}_{2} \mathrm{O}$ e $45 \mu \mathrm{M}$ EDTA bissódico. O Si, fornecido como ácido monosilícico, foi obtido pela passagem do silicato de potássio através de resina de troca de cátions (Amberlite IR-120B, $\mathrm{H}^{+}$forma, Sigma-Aldrich, São Paulo) (Ma e TaKahashi, 2002). As concentrações de Si utilizadas foram de $0 \mathrm{mM}$ e $2 \mathrm{mM}$. A adição do ácido monosilícico à solução nutritiva não alterou o $\mathrm{pH}$. Sementes de algodoeiro dos cultivares NuOpal e BRS Buriti foram esterilizadas em solução de hipoclorito de sódio $10 \%$ por 2 min e, posteriormente, lavadas em água destilada por $3 \mathrm{~min}$ e germinadas em leito de areia lavada e autoclavada. Dez dias após a germinação, cinco plântulas foram transferidas para vasos plásticos contendo $5 \mathrm{~L}$ de solução nutritiva. As plântulas foram mantidas em solução nutritiva com meia força iônica, contendo ou não ácido monosilícico. Após sete dias, a concentração da solução utilizada foi modificada para força total. A solução nutritiva foi aerada, trocada a cada quatro dias ou quando a condutividade elétrica atingiu $85 \%$ do valor inicial. $\mathrm{O} \mathrm{pH}$ da solução nutritiva foi verificado diariamente e mantido a 5,5 $\pm 0,5$ empregando-se soluçóes de $\mathrm{NaOH}$ ou $\mathrm{HCl}(1 \mathrm{M})$, quando necessário. As plantas ficaram nessas condiçôes até o final das avaliaçôes. 
Obtenção e preparo do inóculo de $R$. areola e inoculação das plantas de algodoeiro

Folhas de plantas de algodoeiro do cultivar NuOpal apresentando sintomas da mancha de ramulária foram coletadas no campo para obtenção do inóculo de $R$. areola. $\mathrm{O}$ inóculo foi preparado lavando-se as folhas em água destilada contendo gelatina $(1 \% \mathrm{p} / \mathrm{v})$ com auxílio de um pincel de cerdas macias para remoção dos conídios. Posteriormente, a suspensáo obtida foi filtrada em camada dupla de gaze estéril para retirada de impurezas e ajustada para a concentração $1,5 \times 10^{5}$ conídios $\mathrm{mL}^{-1}$ com o auxílio de um hemacitômetro. Aos 30 dias após emergência, plantas de algodoeiro no estádio V4 (Marur e Ruano, 2001) foram inoculadas com a suspensão de conídios de $R$. areola com auxílio de um atomizador (VLS-Set Airbrush, Paache Airbrush Company, EUA), cobrindo-se homogeneamente as superfícies abaxial e adaxial das folhas. Posteriormente, as plantas foram mantidas em câmara de nevoeiro (temperatura de $25 \pm 2^{\circ} \mathrm{C}$ e umidade relativa de $85 \pm 5 \%$ ) por $48 \mathrm{~h} \mathrm{e,} \mathrm{em} \mathrm{seguida,} \mathrm{transferidas}$ para câmara de crescimento com temperatura de $25 \pm 5^{\circ} \mathrm{C}$ e umidade relativa de $60 \pm 10 \%$, onde permaneceram até o final do experimento.

\section{Avaliação da severidade da mancha de ramulária}

A severidade da mancha de ramulária foi avaliada aos 10 , 12, 15, 18 e 21 dias após inoculação (dai) das plantas $\operatorname{com} R$. areola utilizando-se a escala diagramática proposta por Aquino et al. (2008). Os dados de severidade foram utilizados para calcular a área abaixo da curva do progresso da mancha de ramulária (AACPMR) através da integração trapezoidal das curvas de progresso da doença, de acordo com a fórmula proposta por Shaner e Finney (1977).

\section{Determinação das trocas gasosas}

Para a determinaçáo das trocas gasosas utilizou-se um sistema portátil de medição de trocas gasosas (LC pro+, Analytical Development Company, Hoddesdon, Reino Unido). A taxa líquida de fixação do $\mathrm{CO}_{2}(A)$, a condutância estomática $\left(g_{s}\right)$, a transpiração $(E)$ e a razáo entre concentraçáo interna e ambiente de $\mathrm{CO}_{2}\left(C_{\mathrm{i}} / C_{\mathrm{a}}\right)$ foram determinadas na quarta folha, do ápice para a base, das plantas no estádio V5 (MARUR e RuAno, 2001). As avaliações foram realizadas no período das 07:30 h às 11:30 h, em sistema aberto, sob irradiância de saturação de $1.000 \mu \mathrm{mol} \mathrm{m}^{-2} \mathrm{~s}^{-1}$ e concentração atmosférica de $\mathrm{CO}_{2}\left(\mathrm{C}_{\mathrm{a}}\right)$ de $\approx 390 \mu \mathrm{mol} \mathrm{mol}^{-1}$. A umidade relativa do ar foi de $80 \pm 5 \%$ e a temperatura foliar variou de $27^{\circ} \mathrm{C}$ a $33^{\circ} \mathrm{C}$. Para estimular a atividade plena da maquinaria fotossintética, as plantas foram mantidas por $30 \mathrm{~min}$ fora da câmara de nebulização, sob pleno sol, antes das avaliaçôes. As mediçôes foram realizadas aos 12, 15, 18 e 21 dai. As avaliaçóes também foram realizadas nas plantas não inoculadas com $R$. areola $(0 \mathrm{~h})$.

\section{Determinação da concentração de pigmentos}

Amostras de 100 mg da quarta folha do ápice para a base das plantas das repetiçóes de cada tratamento foram coletadas aos 12, 15, 18 e 21 dai. Folhas coletadas de plantas não inoculadas com $R$. areola $(0 \mathrm{~h})$ serviram como controle. As amostras foram trituradas em nitrogênio líquido contendo $0,1 \mathrm{~g}$ de carbonato de cálcio e, em seguida, homogeneizadas com $2 \mathrm{~mL}$ de acetona $80 \%(\mathrm{v} / \mathrm{v})$ por $1 \mathrm{~min}$ sob luz verde. A suspensão resultante foi filtrada em papel de filtro Whatman \# 1 . O resíduo foi lavado por três vezes em acetona a $80 \%$ e o volume final completado em balão volumétrico para $25 \mathrm{~mL}$ com o mesmo solvente. As absorbâncias dos extratos foram lidas em espectrofotômetro nos comprimentos de onda de $470 \mathrm{~nm}, 646,8 \mathrm{~nm}$ e 663,2 nm. As concentraçóes de clorofila $a\left(\mathrm{Cl}_{a}\right)$, clorofila $b\left(\mathrm{Cl}_{b}\right)$ e de carotenóides foram estimadas de acordo com Lichtenthaler (1987).

\section{Determinação das atividades da dismutase do superóxido, da catalase, da peroxidase do ascorbato e da redutase da glutationa}

Amostras da terceira, quarta e quinta folhas do ápice para a base das plantas das repetiçóes de cada tratamento foram coletadas aos 12, 15, 18 e 21 dai a partir das 08:00 h da manhã. Folhas coletadas de plantas não inoculadas com $R$. areola $(0 \mathrm{~h})$ serviram como controle. As amostras foram coletadas individualmente em envelopes de papel alumínio devidamente identificados e rapidamente mantidas em nitrogênio líquido durante a coleta e, em seguida, armazenadas a $-80^{\circ} \mathrm{C}$ até análise.

O extrato enzimático foi obtido de acordo com o método de Havir e Mchale (1987) com algumas modificaçóes. Foram macerados $0,3 \mathrm{~g}$ de massa foliar fresca com nitrogênio líquido em almofariz até a obtenção de um pó fino. O pó obtido foi homogeneizado em $2 \mathrm{~mL}$ de tampão fosfato de potássio $50 \mathrm{mM}$ (pH 6,8) contendo $0,1 \mathrm{mM}$ de ácido etilenodiamino tetra-acético (EDTA), $1 \mathrm{mM}$ de fenilmetilsulfonilfúor (PMSF) e 2\% de polivinilpolipirrolidona (PVPP). O homogeneizado foi centrifugado a $1.500 \mathrm{~g}$ por $15 \mathrm{~min}$ a $4^{\circ} \mathrm{C}$.

A atividade da dismutase do superóxido (SOD, EC 1.15.1.1) foi determinada pela adição de $30 \mu \mathrm{L}$ do extrato enzimático em $2,97 \mathrm{~mL}$ de mistura de reação constituída de tampão fosfato de sódio $50 \mathrm{mM}(\mathrm{pH} 7,8)$, metionina $13 \mathrm{mM}$, azul de $p$-nitro-tetrazólio (NBT) $75 \mu \mathrm{M}$, EDTA 0,1 mM e riboflavina $2 \mu \mathrm{M}$ (Giannopolitis e Ries, 1977). A reação ocorreu a $25^{\circ} \mathrm{C}$ sob iluminaçáo de lâmpadas de $15 \mathrm{~W}$. Após 5 min de exposição à luz, a iluminação foi interrompida e a 
formazana azul, produzida pela fotorredução do NBT, foi medida a $560 \mathrm{~nm}$ em espectrofotômetro (GIANNOPOLITIS e RiEs, 1977). As amostras controle tiveram absorbâncias medidas a $560 \mathrm{~nm}$ em espectrofotômetro utilizando-se a mistura de reação mantida no escuro por $5 \mathrm{~min}$. Os valores obtidos foram subtraídos das leituras das amostras das repetiçóes dos tratamentos que receberam iluminação. Uma unidade da SOD foi definida como a quantidade de enzima necessária para inibir em $50 \%$ a fotorreduçáo do NBT (Peixoto et al., 1999). A atividade da SOD foi expressa em unidades $(\mathrm{U}) \mathrm{min}^{-1} \mathrm{mg}^{-1}$ de proteína.

A atividade da catalase (CAT, EC 1.11.1.6) foi determinada pelo método de CAKMAK et al. (1993). A mistura de reação foi constituída de $50 \mathrm{mM}$ de tampão fosfato de potássio (pH 6,8) e 12,5 mM de $\mathrm{H}_{2} \mathrm{O}_{2}$ num volume de $1 \mathrm{~mL}$. A reação foi iniciada pela adição de $0,35 \mathrm{~mL}$ do extrato da enzima e a atividade foi determinada pelo consumo de $\mathrm{H}_{2} \mathrm{O}_{2}$ durante 1 min a $240 \mathrm{~nm}$ em espectrofotômetro. Coeficiente de extinçáo molar de $39,4 \mathrm{mM}^{-1} \mathrm{~cm}^{-1}$ foi usado para determinar a atividade da CAT, a qual foi expressa em mmol $\mathrm{min}^{-1} \mathrm{mg}^{-1}$ de proteína.

A atividade da peroxidase do ascorbato (APX, EC 1.11.1.11) foi determinada pelo método de NaKano e Asada (1981). A mistura de reação foi constituída de $50 \mathrm{mM}$ de tampão fosfato de potássio $(\mathrm{pH} 6,8), 1 \mathrm{mM}$ de $\mathrm{H}_{2} \mathrm{O}_{2}$ e $0,8 \mathrm{mM}$ de ascorbato num volume de $1 \mathrm{~mL}$. A reação foi iniciada pela adição de $34 \mu \mathrm{L}$ do extrato da enzima e a atividade foi determinada pela oxidaçáo do $\mathrm{H}_{2} \mathrm{O}_{2}$ dependente do ascorbato durante $1 \mathrm{~min}$ a $290 \mathrm{~nm}$ em espectrofotômetro. $\mathrm{O}$ coeficiente de extinção molar de $2,8 \mathrm{mM} \mathrm{cm}^{-1}$ foi usado para calcular a atividade da APX, a

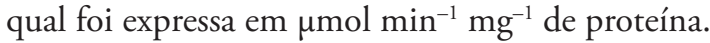

Para obtenção do extrato da redutase da glutationa (GR, EC 1.8.1.7), 0,3 g de tecido foliar foram macerados com nitrogênio líquido em almofariz até a obtenção de um pó fino. $\mathrm{O}$ pó obtido foi homogeneizado em $2 \mathrm{~mL}$ de tampão fosfato de potássio $100 \mathrm{mM}(\mathrm{pH} 7,5)$, EDTA 0,1 mM, $D L$-ditioteitol $1 \mathrm{mM}$, PMSF $1 \mathrm{mM}$ e PVPP $2 \%$ $(\mathrm{p} / \mathrm{v})$. O homogeneizado foi centrifugado a $1.500 \mathrm{~g}$ por 15 min a $4^{\circ} \mathrm{C}$ e o sobrenadante foi usado como extrato da enzima. A atividade da GR foi determinada pela adição de $100 \mu \mathrm{L}$ do extrato enzimático em $0,9 \mathrm{~mL}$ de uma mistura de reação constituída de tampão fosfato de potássio $0,1 \mathrm{M}$ ( $\mathrm{pH} 7,5)$, EDTA $1 \mathrm{mM}$, glutationa oxidada $1 \mathrm{mM}$ e NADPH $0,1 \mathrm{mM}$ preparado em tampão Tris- $\mathrm{HCl} 0,5 \mathrm{mM}(\mathrm{pH} 7,5)$ segundo Carlberg e MANNERVIK (1985). O decréscimo na absorbância a $340 \mathrm{~nm}$ em espectrofotômetro na temperatura de $30^{\circ} \mathrm{C}$ foi medido no primeiro minuto após o início da reação. A atividade da GR foi calculada utilizando-se o coeficiente de extinção molar de $6,22 \mathrm{mM} \mathrm{cm}^{-1}$ (Foyer e Halliwell, 1976). A atividade da GR foi expressa em $\mathrm{mmol} \mathrm{min}^{-1} \mathrm{mg}^{-1}$ de proteína.
A concentração de proteínas em cada amostra foi determinada pelo método de BRADFORD (1976) e todas as determinações enzimáticas foram realizadas em triplicata.

\section{Determinação da concentração de peróxido de hidrogênio $\left(\mathrm{H}_{2} \mathrm{O}_{2}\right)$}

Uma amostra de 0,2 $\mathrm{g}$ de massa foliar fresca foi macerada com nitrogênio líquido em almofariz até a obtenção de um pó fino. $\mathrm{O}$ pó obtido foi homogeneizado em $2 \mathrm{~mL}$ de tampão fosfato de potássio $50 \mathrm{mM}(\mathrm{pH}$ 6,5) contendo hidroxilamina $1 \mathrm{mM}$. O homogeneizado foi centrifugado a $10.000 \mathrm{~g}$ por $15 \mathrm{~min}$ a $4^{\circ} \mathrm{C}$ e o sobrenadante foi usado para determinar a concentração de $\mathrm{H}_{2} \mathrm{O}_{2}$ (KuO e KaO, 2003). Uma alíquota de $100 \mu \mathrm{L}$ do sobrenadante foi adicionada a um meio de reação constituído de $\mathrm{FeNH}_{4}\left(\mathrm{SO}_{4}\right) 100 \mu \mathrm{M}$, ácido sulfúrico $25 \mathrm{mM}$, laranja de xilenol $250 \mu \mathrm{M}$ e sorbitol $100 \mathrm{mM}$ em um volume final de $2 \mathrm{~mL}$ (GAY e GeBICKI, 2000). As amostras foram mantidas no escuro por $30 \mathrm{~min} e$ a absorbância determinada a $560 \mathrm{~nm}$ em espectrofotômetro. As concentraçóes de $\mathrm{H}_{2} \mathrm{O}_{2}$ foram estimadas com base em curva de calibração preparada com soluçóes de $\mathrm{H}_{2} \mathrm{O}_{2}$. Os resultados foram expressos em mmol de $\mathrm{H}_{2} \mathrm{O}_{2} \mathrm{~g}^{-1}$ de matéria fresca (Gay e Gebicki, 2000).

\section{Determinação da concentração de aldeído malônico (MDA)}

Foram macerados $0,2 \mathrm{~g}$ de massa foliar fresca em nitrogênio líquido seguido de homogeneização em $2 \mathrm{~mL}$ de ácido tricloroacético (TCA) $(0,1 \% \mathrm{p} / \mathrm{v})$. O homogeneizado foi centrifugado a $10.000 \mathrm{~g}$ por $15 \mathrm{~min}$ a $4^{\circ} \mathrm{C}$ e o sobrenadante foi coletado e utilizado nas determinaçóes das concentraçóes de MDA. Foram adicionados $500 \mu \mathrm{L}$ do sobrenadante em um tubo de microcentrífuga contendo $1,5 \mathrm{~mL}$ da solução de ácido tiobarbitúrico (TBA) (0,5\%) em TCA 20\%. As amostras foram incubadas por $2 \mathrm{~h}$ a $90^{\circ} \mathrm{C}$ em banho-maria. A reação foi parada em banho de gelo por $5 \mathrm{~min}$. As amostras foram centrifugadas a $13.000 \mathrm{~g}$ por $4 \mathrm{~min}$. A absorbância da mistura da reação foi determinada a $532 \mathrm{~nm}$ em espectrofotômetro. Utilizou-se para os cálculos, o coeficiente de absortividade molar de $155 \mathrm{mM} \mathrm{cm}^{-1} \mathrm{e}$ os resultados foram expressos em $\mathrm{nmol} \mathrm{g}^{-1}$ de material vegetal fresco (Сакмак е Ноsт, 1991).

\section{Determinação do extravasamento de eletrólitos (EE)}

$\mathrm{O}$ EE foi determinado conforme metodologia descrita por Lima et al. (2002) com algumas modificaçôes. Amostras da quarta e quinta folhas do ápice para a base das plantas das repetiçóes de cada tratamento foram coletadas aos 12,15 , 18, 21 dai a partir das 08:00 h da manhã. Folhas coletadas de plantas náo inoculadas com $R$. areola $(0 \mathrm{~h})$ serviram como 
controle. Um total de 22 discos de $1 \mathrm{~cm}^{2}$ foram obtidos das folhas, lavados por duas vezes em água desionizada e colocados em $60 \mathrm{~mL}$ de água desionizada a $25^{\circ} \mathrm{C}$. Após $4 \mathrm{~h}$, foi realizada a primeira leitura da condutividade elétrica (CE1) em condutivímetro. Em seguida, as amostras foram incubadas a $90^{\circ} \mathrm{C}$ por $2 \mathrm{~h}$ sendo, então, determinada a segunda leitura da condutividade elétrica (CE2). O EE, em porcentagem, foi obtido de acordo com a seguinte fórmula: $\mathrm{EE}(\%)=(\mathrm{CE} 1 / \mathrm{CE} 2) \times 100$.

\section{Determinação da atividade da lipoxigenase}

Para obtenção do extrato para determinação enzimática da lipoxigenase (LOX, EC 1.13.11.12), 0,2 g de massa foliar fresca foram macerados com nitrogênio líquido em almofariz com adição de PVPP até obtenção de um pó fino. O pó obtido foi homogeneizado em $2 \mathrm{~mL}$ de tampão fosfato de potássio $100 \mathrm{mM}$ (pH 6,8) contendo $1 \mathrm{mM}$ de fluoreto de PMSF e 0,1 mM EDTA. O homogeneizado foi centrifugado a $12.000 \mathrm{~g}$ por $20 \mathrm{~min}$ a $4^{\circ} \mathrm{C}$. O sobrenadante foi usado como extrato para determinaçáo da atividade da LOX. A reação foi iniciada após adição de $0,3 \mathrm{~mL}$ do extrato a uma mistura contendo $2 \mathrm{~mL}$ de tampáo fosfato de sódio $50 \mathrm{mM}(\mathrm{pH} 6,0)$ e $0,3 \mu \mathrm{L}$ do substrato linoleato de sódio $10 \mathrm{mM}$. A mistura foi incubada em banho-maria por 4 min a $25^{\circ} \mathrm{C}$. A atividade da LOX foi determinada conforme metodologia descrita por AXELROD et al. (1981). A absorbância da mistura da reação foi determinada a cada $10 \mathrm{~s}$ em espectrofotômetro a $234 \mathrm{~nm}$ por um período de 2 min. Utilizou-se para os cálculos o coeficiente de extinção molar de $25.000 \mathrm{M} \mathrm{cm}^{-1}$ e os resultados foram expressos em $\mu \mathrm{mol} \mathrm{min}{ }^{-1} \mathrm{mg}^{-1}$ de proteína.

As determinaçóes enzimáticas foram realizadas em triplicata. A concentração de proteínas utilizada para o cálculo da atividade da LOX de cada amostra foi determinada de acordo com BRADFORD (1976).

\section{Determinação da concentração foliar de Si}

Após o término do experimento, as folhas das plantas das repetiçóes de cada tratamento foram coletadas, lavadas em água destilada e secadas em estufa com circulação forçada de ar a $70^{\circ} \mathrm{C}$ durante $72 \mathrm{~h}$. Posteriormente, as folhas foram moídas em moinho tipo Thomas-Wiley (Thomas Scientific, Swedesboro, NJ) equipado com peneira de 40 mesh. A concentração foliar de Si foi determinada por análise colorimétrica da digestáo alcalina de $0,1 \mathrm{~g}$ de tecido foliar seco (KorNDÖRfER et al., 2004).

\section{Delineamento experimental e análise estatística dos dados}

Foram conduzidos dois experimentos, sendo o primeiro para avaliar a severidade da mancha de ramulária e determinar a concentração foliar de $\mathrm{Si}$ (experimento 1) e o segundo para avaliar as trocas gasosas e obter as amostras para as análises bioquímicas (experimento 2). $\mathrm{O}$ experimento 1 foi instalado em delineamento inteiramente casualizado num esquema fatorial $2 \times 2$ com quatro repetiçóes. Os fatores estudados foram dois cultivares de algodoeiro e duas doses de Si. O experimento 2 foi instalado em delineamento em blocos casualizados em esquema fatorial $2 \times 2 \times 2 \mathrm{com}$ 10 repetiçôes. Os fatores estudados foram dois cultivares, duas doses de $\mathrm{Si}$ e plantas inoculadas ou náo com $R$. areola. Cada unidade experimental foi constituída por um vaso plástico contendo cinco plantas de algodoeiro. Os dados obtidos foram submetidos à análise de variância (ANOVA) e as médias dos tratamentos foram comparadas pelo teste de Tukey ou teste de $t$ de Student $(\mathrm{p} \leq 0,05)$ utilizando-se o programa SAEG 9.1 (SAEG, 2007). A AACPMR foi correlacionada com os parâmetros fotossintéticos e esses foram correlacionados entre eles.

\section{RESULTADOS}

\section{AACPMR e concentração foliar de Si}

Houve interação significativa $(\mathrm{F}=5,91)$ entre os fatores cultivares $\times$ doses de Si para a AACPMR e para a concentração foliar de $\mathrm{Si}(\mathrm{F}=3,18)$. A concentração foliar de $\mathrm{Si}$ aumentou significativamente e foi acompanhada de decréscimo na AACPMR nas plantas dos dois cultivares supridas com Si em relaçáo às plantas não supridas com esse elemento.

\section{Atividades das enzimas relacionadas com o estresse oxidativo}

A atividade da SOD nas plantas do cultivar $\mathrm{NuOpal}$ supridas com Si aumentou significativamente aos 0 e 15 dai (Figura 1a) e nas plantas do cultivar BRS Buriti até os 15 dai em relação às plantas não supridas com Si (Figura $1 \mathrm{~b}$ ). A atividade da CAT aumentou significativamente nas plantas dos dois cultivares não supridas com $\mathrm{Si}$ dos 12 aos 21 dai em relação às plantas supridas com $\mathrm{Si}$ (Figuras $1 \mathrm{c}, \mathrm{d}$ ). Houve aumento significativo na atividade da CAT nas plantas dos dois cultivares supridas com $\mathrm{Si}$ apenas aos 0 dai em relação às plantas não supridas com Si (Figuras 1c,d). A atividade da APX nas plantas do cultivar NuOpal supridas com $\mathrm{Si}$ aumentou significativamente até os 18 dai, enquanto que nas plantas do cultivar BRS Buriti esse aumento se estendeu até os 21 dai em relação às plantas não supridas com $\mathrm{Si}$ (Figuras 1e,f). A atividade da GR nas plantas do cultivar $\mathrm{NuOpal}$ não supridas com $\mathrm{Si}$ aumentou significativamente aos 0 e 15 dai (Figura 1g) e nas plantas do cultivar BRS Buriti, apenas aos 15 dai, em relação às plantas supridas com $\mathrm{Si}$ (Figura 1h). Houve aumento significativo na atividade da GR nas plantas do cultivar NuOpal supridas com Si apenas aos 21 dai (Figura 1g) e nas plantas do cultivar BRS Buriti, 
aos 0, 12 e 21 dai, em relação às plantas não supridas com Si (Figura 1h).

\section{Concentração de $\mathrm{H}_{2} \mathrm{O}_{2}$ e MDA e extravazamento de eletrólitos}

A concentração de $\mathrm{H}_{2} \mathrm{O}_{2}$ aumentou significativamente nas plantas dos dois cultivares não supridas com Si aos 15 dai em relação às plantas supridas com Si (Figuras 2a,b).

As maiores concentraçôes de MDA ocorreram nas plantas dos dois cultivares não supridas com Si até os
15 dai em relaçáo às plantas supridas com esse elemento (Figuras 2c,d).

$\mathrm{O}$ EE aumentou significativamente nas plantas dos cultivares $\mathrm{NuOpal}$ e BRS Buriti não supridas com Si dos 0 aos 21 dai e dos 15 aos 21 dai, respectivamente, em relação às plantas supridas com Si (Figuras $2 \mathrm{e}, \mathrm{f}$ ).

\section{Atividade da LOX}

A atividade da LOX aumentou significativamente nas plantas do cultivar NuOpal supridas com Si aos 0, 12 e 18 dai em

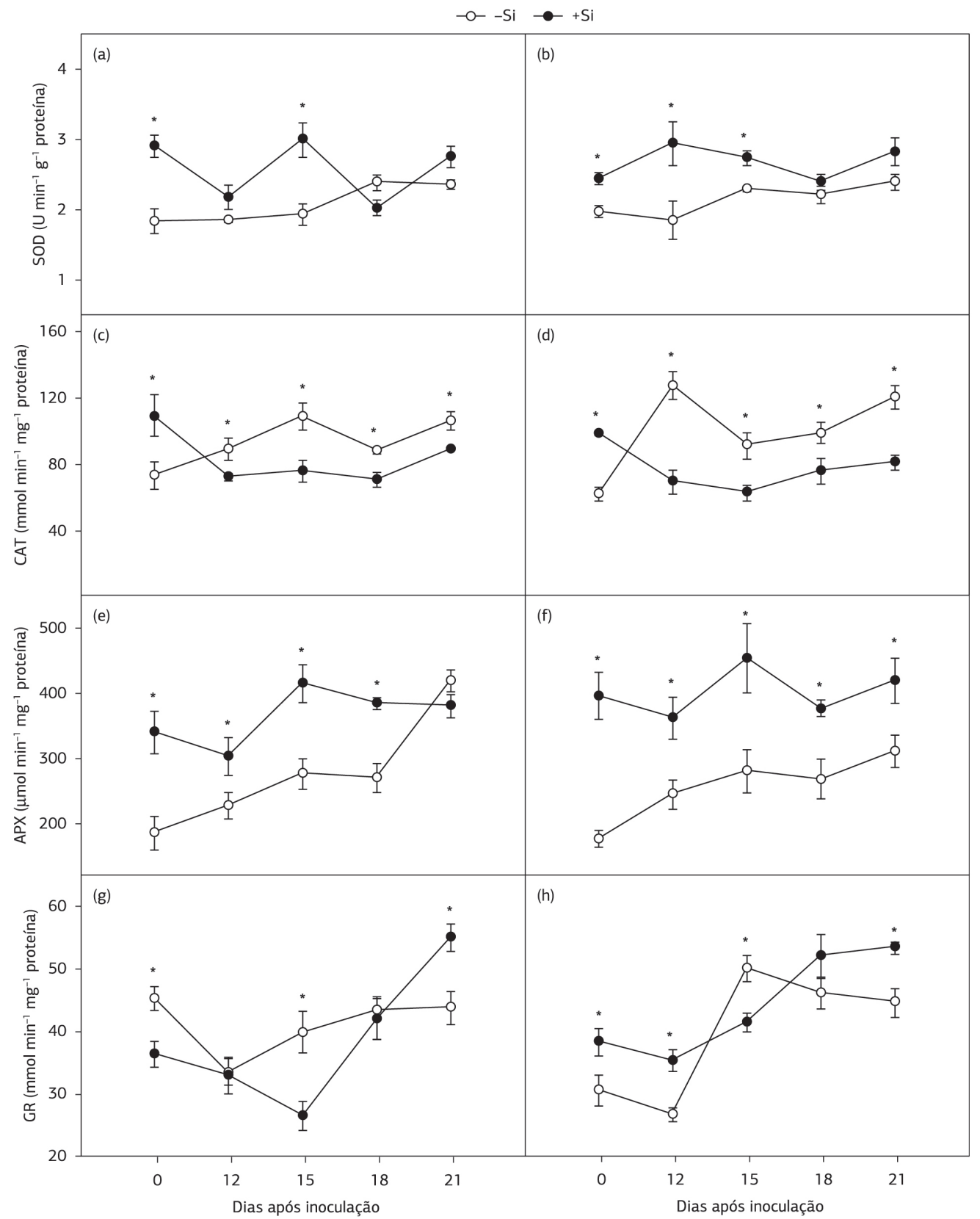

Figura 1. Atividade da superóxido dismutase (SOD) (a, b), catalase (CAT) (c, d), ascorbato peroxidase (APX) (e, f) e glutationa redutase (GR) (g, h) em folhas de plantas de algodoeiro dos cultivares NuOpal (a, c, e, g) e BRS Buriti (b, d, f, h) cultivadas em solução nutritiva contendo $0(-\mathrm{Si})$ ou $2 \mathrm{mM}$ de silício $(+\mathrm{Si})$ e inoculadas com Ramularia areola; barras em cada ponto representam o desvio padrão da média; médias dos tratamentos $-\mathrm{Si} \mathrm{e}+\mathrm{Si}$ seguidas de asterisco $\left({ }^{*}\right)$ são significativamente diferentes $(\mathrm{p} \leq 0,05)$ pelo teste- $t$; $n=4$. 
relação às plantas não supridas com $\mathrm{Si}$ (Figura $2 \mathrm{~g}$ ). Houve aumento significativo na atividade da LOX nas plantas do cultivar $\mathrm{NuOpal}$ não supridas com $\mathrm{Si}$ aos 15 dai em relação às plantas supridas com Si (Figura 2g). A atividade da LOX aumentou significativamente nas plantas da cultivar BRS Buriti supridas com Si apenas aos 12 dai em comparação com as plantas não supridas com Si (Figura $2 \mathrm{~h}$ ). Houve aumento significativo na atividade da LOX nas plantas do cultivar BRS Buriti não supridas com Si aos 15 e 21 dai em relação às plantas supridas com $\mathrm{Si}$ (Figura $2 \mathrm{~h}$ ).

\section{Trocas gasosas}

Houve efeito significativo do fator cultivares, respectivamente, para os parâmetros $A, g_{\mathrm{s}}$ e $E(\mathrm{~F}=125,36,78,09$ e 37,35). A interação entre os fatores cultivares $\times$ inoculação foi significativa para os parâmetros $A$ e $g_{\mathrm{s}}(\mathrm{F}=154,95$ e 154,55, respectivamente); a interação entre os fatores cultivares $\times$ doses de Si foi significativa para as variáveis $g_{\mathrm{s}}$ e $E(\mathrm{~F}=4,46 \mathrm{e}$ 8,14 , respectivamente); a interação entre os fatores inoculação $\times$ doses de $S i$ foi significativa para as variáveis $A, g_{s}$ e $E$

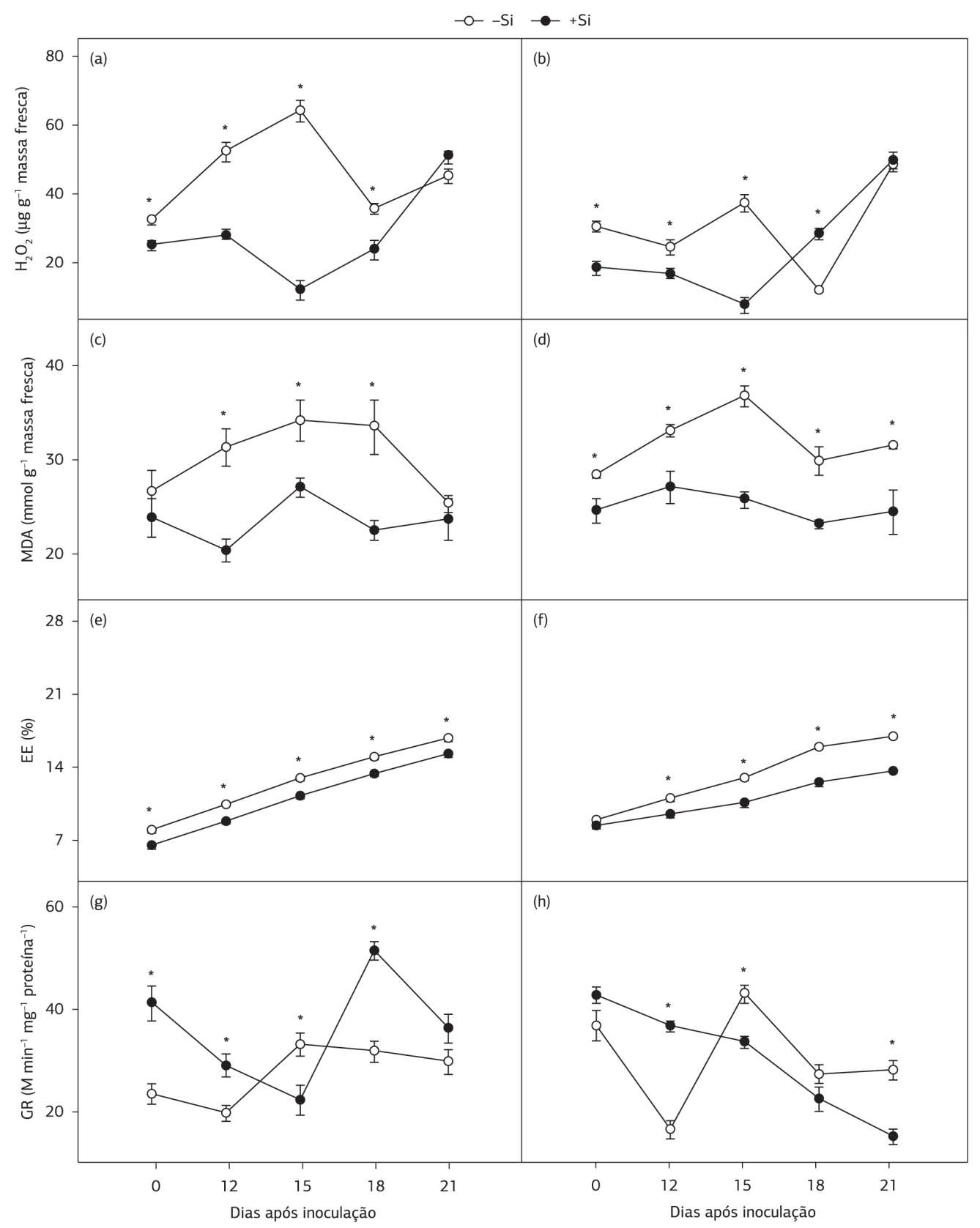

Figura 2. Concentração de peróxido de hidrogênio $\left(\mathrm{H}_{2} \mathrm{O}_{2}\right)(\mathrm{a}, \mathrm{b})$ e de aldeído malônico (MDA) (c, d), extravazamento de eletrólitos (EE) $(e, f)$ e atividade de lipoxigenases (LOX) (, $\mathrm{h}$ ) em folhas de plantas de algodoeiro dos cultivares NuOpal (a, c, e, g) e BRS Buriti (b, d, f, h) cultivadas em soluçáo nutritiva contendo $0(-\mathrm{Si})$ ou $2 \mathrm{mM}$ de silício $(+\mathrm{Si})$ e inoculadas com Ramularia areola; barras em cada ponto representam o desvio padrão da média; médias dos tratamentos $-\mathrm{Si}$ e $+\mathrm{Si}$ seguidas de asterisco $\left(^{*}\right)$ são significativamente diferentes $(\mathrm{p} \leq 0,05)$ pelo teste- $t ; n=4 ; \mathrm{MF}=$ massa fresca. 
$(\mathrm{F}=8,84,7,48$ e 10,55 , respectivamente $) ;$ e a interação entre os fatores cultivares $\times$ inoculação $\times$ doses de $\mathrm{Si}$ foi significativa para os parâmetros $A, g_{\mathrm{s}}$ e $E(\mathrm{~F}=11,85,30,71$ e 8,05 , respectivamente).

Os valores de $A$ e $g_{s}$ aumentaram significativamente nas plantas do cultivar $\mathrm{NuOpal}$ supridas com $\mathrm{Si}$ e não inoculadas com $R$. areola aos 12, 15, 18 e 21 dai (Figuras 3a e 4a) e nas plantas do cultivar BRS Buriti supridas com $\mathrm{Si}$ e não inoculadas com $R$. areola aos 15, 18 e 21 dai quando comparadas com as plantas não supridas com Si (Figuras 3b e 4b). Os valores de $A$ foram menores em todas as épocas de avaliação para as plantas do cultivar $\mathrm{NuOpal}$ inoculadas e supridas com Si (Figura 3c) e nas plantas do cultivar BRS Buriti (Figura 3d) em relação às plantas não inoculadas, porém foram superiores às plantas não supridas com $\mathrm{Si}$ (Figuras $3 \mathrm{c}, \mathrm{d}$ ). Houve decréscimo em $g_{\mathrm{s}}$ nas plantas inoculadas e supridas com Si do cultivar NuOpal (Figura 4c) e nas plantas do cultivar BRS Buriti (Figura 4d) quando comparadas com as plantas não inoculadas, porém esses decréscimos foram maiores nas plantas não supridas com Si. A $E$ aumentou significativamente nas plantas não inoculadas e supridas com Si do cultivar NuOpal aos 0, 12, 15 e 18 dai (Figura 5a) e nas plantas náo inoculadas e supridas com $\mathrm{Si}$ do cultivar BRS Buriti aos 0, 15, 18 e 21 dai (Figura 5b), quando comparadas com as plantas não supridas com $\mathrm{Si}$. A $E$ decresceu nas plantas inoculadas e não supridas com $\mathrm{Si}$ do cultivar NuOpal (Figura 5c) e nas plantas inoculadas e náo supridas com Si do cultivar BRS Buriti (Figura 5d). A razão $\left(C_{\mathrm{i}} / C_{\mathrm{a}}\right)$ aumentou significativamente nas plantas não inoculadas e não supridas com $\mathrm{Si}$ do cultivar $\mathrm{NuOpal}$ aos 12, 18 e 21 dai (Figura 6a) e nas plantas não inoculadas e não supridas com Si do cultivar BRS Buriti aos 15 e 18 dai (Figura 6b), quando comparadas com as plantas supridas com Si. Houve decréscimo na razão $\left(C_{i} / C_{2}\right)$ nas plantas inoculadas e supridas com Si do cultivar NuOpal (Figura 6c) e nas plantas inoculadas e supridas com Si do cultivar BRS Buriti (Figura 6d), em relação às plantas não inoculadas dos dois cultivares, porém esses decréscimos foram maiores nas plantas não supridas com esse elemento.

\section{Concentração de pigmentos}

Nas plantas do cultivar NuOpal supridas com Si houve aumento significativo na concentração de $\mathrm{Cl}_{a}$ aos 18 e 21 dai (Figura 7a), na concentração de $\mathrm{cl}_{\mathrm{b}}$ apenas aos 21 dai (Figura $7 \mathrm{~b}$ ), na relação $\mathrm{Cl}_{a} / \mathrm{Cl}_{b}$ aos 0,12 e 18 dai (Figura $7 \mathrm{c}$ ) e na concentração de carotenóides aos 0,12 e 18 dai (Figura $7 \mathrm{~d}$ ), em relação às plantas não supridas com $\mathrm{Si}$. Nas plantas do cultivar BRS Buriti supridas com $\mathrm{Si}$, as concentraçōes de $\mathrm{Cl}_{a}$ e de $\mathrm{Cl}_{b}$ aumentaram significativamente apenas aos 18 dai (Figuras 8a,b), houve redução da relação $\mathrm{Cl}_{a} / \mathrm{Cl}_{b}$ (Figura 8c) e, para a concentração de carotenóides, os maiores valores ocorreram aos 12 dai (Figura $8 \mathrm{~d}$ ), em relação às plantas não supridas com Si.

\section{Correlação de Pearson}

Houve correlação negativa e significativa entre a AACPMR e os parâmetros $A, g_{\mathrm{s}}, E \mathrm{e}\left(C_{\mathrm{i}} / C_{\mathrm{a}}\right)$ nas plantas dos dois cultivares supridas com $\mathrm{Si}$ (Tabelas 1 e 2).

\section{DISCUSSÃO}

No presente estudo, os parâmetros de trocas gasosas $A, g_{\mathrm{s}}$ e $E$ mostraram-se maiores nas plantas supridas com $\mathrm{Si}$ e infectadas por $R$. areola e houve uma redução da AACPMR em relação às plantas não supridas com esse elemento, fortalecendo a hipótese de que o Si pode minimizar os danos causados por $R$. areola em plantas de algodoeiro. Danos nos fotossistemas do aparato fotossintético em decorrência da infecção por $R$. areola em plantas de algodoeiro podem ter contribuído para os baixos valores dos parâmetros de trocas gasosas, principalmente $A$ e $g_{s}$, na presença ou não de Si. Decréscimos paralelos em $A$ e $g_{s}$ mostram que o fechamento estomático esteve envolvido na redução da fotossíntese durante o processo infeccioso de $R$. areola. É provável que as atividades das enzimas envolvidas na fixação do $\mathrm{CO}_{2}$

Tabela 1. Valores de correlaçáo de Pearson (acima da diagonal) e respectivos valores de probabilidade (abaixo da diagonal) entre as variáveis taxa de assimilação líquida de $\mathrm{CO}_{2}(A)$, condutância estomática $(g)$, transpiração $(E)$, razão entre concentração interna e do ambiente de $\mathrm{CO}_{2}\left(C_{\mathrm{i}} / C_{\mathrm{a}}\right)$ e área abaixo da curva do progresso da mancha de ramulária (AACPMR) avaliadas nas plantas de algodoeiro do cultivar $\mathrm{NuOpal}$ supridas ou náo com silício e inoculadas com Ramularia areola

\begin{tabular}{cccccc} 
Variáveis & $\boldsymbol{A}$ & $\boldsymbol{g}_{\mathrm{s}}$ & $\boldsymbol{E}$ & $\boldsymbol{C}_{\mathrm{i}} / \mathbf{C}_{\mathrm{a}}$ & AACPMR \\
$A$ & - & $0,91^{*}$ & $0,83^{*}$ & $0,97^{*}$ & $-0,85^{*}$ \\
$g_{\mathrm{s}}$ & 0,0142 & - & $0,84^{*}$ & $0,97^{*}$ & $-0,90^{*}$ \\
$E$ & 0,0370 & 0,0369 & - & $0,88^{*}$ & $-0,97^{*}$ \\
$C_{\mathrm{i}} / C_{\mathrm{a}}$ & 0,0021 & 0,0020 & 0,0221 & - & $-0,91^{*}$ \\
AACPMR & 0,0033 & 0,0001 & 0,0012 & 0,0002 & - \\
\hline * significativo a $\mathrm{p} \leq 0,05$ & & & &
\end{tabular}

Tabela 2. Valores de correlação de Pearson (acima da diagonal) e respectivos valores de probabilidade (abaixo da diagonal) entre as variáveis taxa de assimilação líquida de carbono $(A)$, condutância estomática $\left(g_{s}\right)$, transpiração $(E)$, razão entre concentração interna e do ambiente de $\mathrm{CO}_{2}\left(C_{i} / C\right)$ e área abaixo da curva do progresso da mancha de ramulária (AACPMR) avaliadas nas plantas de algodoeiro do cultivar BRS Buriti supridas ou náo com silício e inoculadas com Ramularia areola

\begin{tabular}{cccccc|} 
Variáveis & $\boldsymbol{A}$ & $\mathbf{g}_{\mathrm{s}}$ & $\boldsymbol{E}$ & $\boldsymbol{C}_{\mathrm{i}} / \mathbf{C}_{\mathrm{a}}$ & AACPMR \\
$A$ & - & $0,98^{*}$ & $0,94^{*}$ & $0,94^{*}$ & $-0,92^{*}$ \\
$g_{\mathrm{s}}$ & 0,0006 & - & $0,89^{*}$ & $0,92^{*}$ & $-0,86^{*}$ \\
$E$ & 0,0083 & 0,0203 & - & $0,87^{*}$ & $-0,93^{*}$ \\
$C_{\mathrm{i}} / C_{\mathrm{a}}$ & 0,0067 & 0,0128 & 0,0246 & - & $-0,96^{*}$ \\
\hline AACPMR & 0,0010 & 0,0001 & 0,0010 & 0,0001 & - \\
\hline
\end{tabular}

${ }^{*}=$ significativo a $\mathrm{p} \leq 0,05$ 


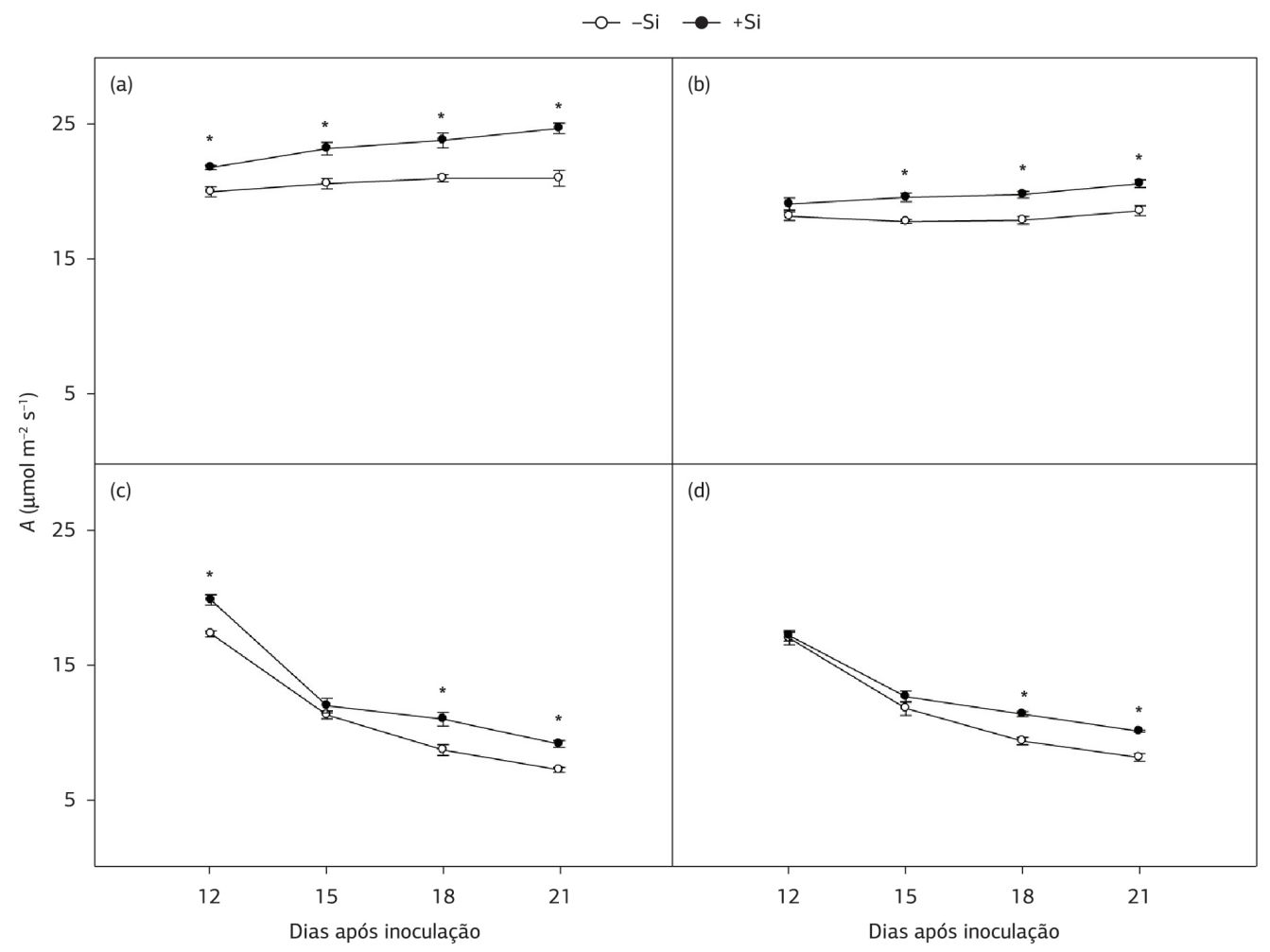

Figura 3. Taxa de assimilaçấo líquida de $\mathrm{CO}_{2}(A)$ em folhas de plantas de algodoeiro dos cultivares NuOpal (a, c) e BRS Buriti (b, d) cultivadas em solução nutritiva contendo $0(-\mathrm{Si})$ ou $2 \mathrm{mM}$ de silício $(+\mathrm{Si})$ e não inoculadas $(\mathrm{a}, \mathrm{b})$ ou inoculadas $(\mathrm{c}, \mathrm{d})$ com Ramularia areola; barras em cada ponto representam o desvio padrão da média; médias dos tratamentos $-\mathrm{Si} \mathrm{e}+\mathrm{Si}$ seguidas de asterisco $\left({ }^{*}\right)$ são significativamente diferentes $(\mathrm{p} \leq 0,05)$ pelo teste- $t ; n=10$.

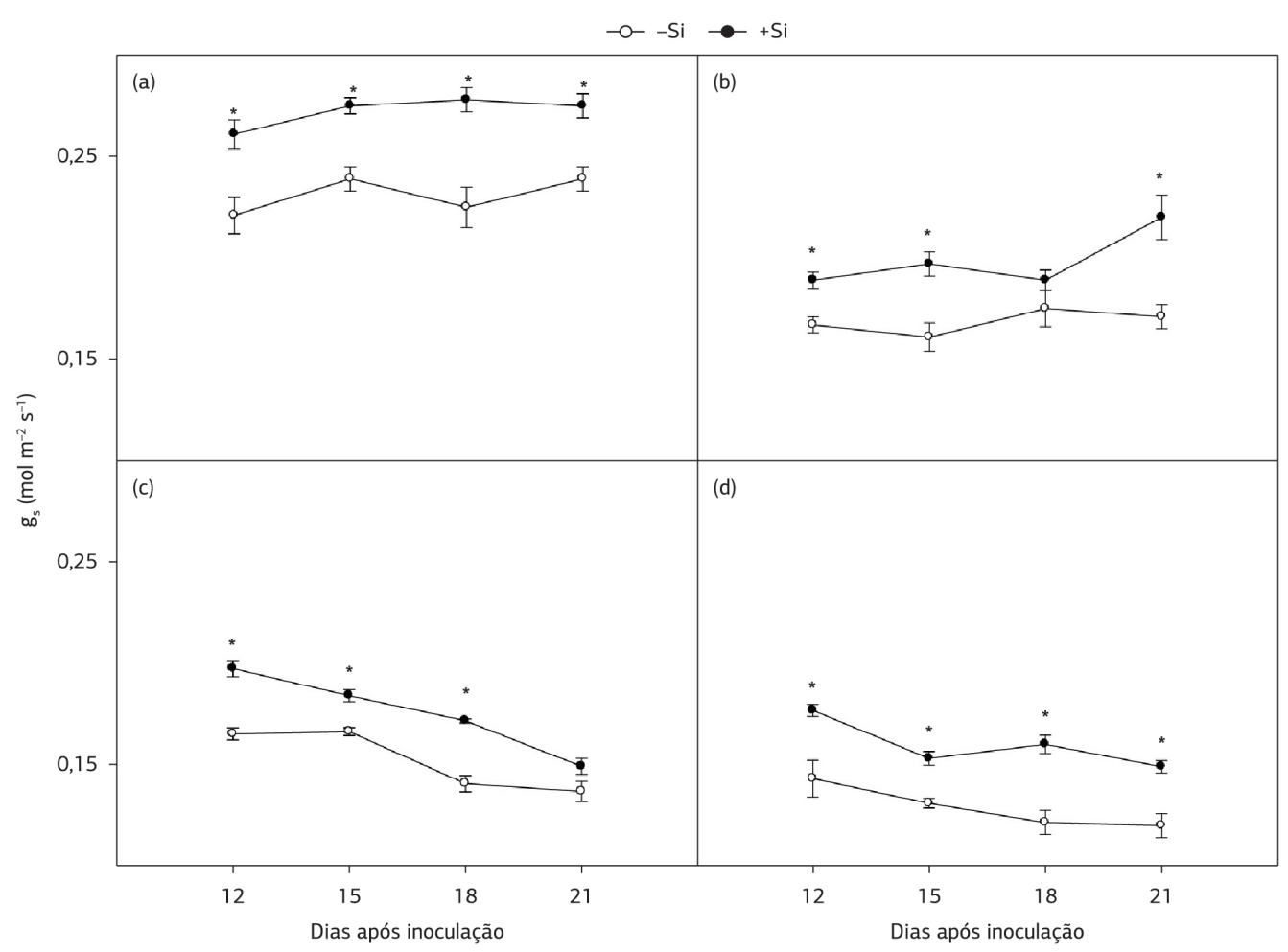

Figura 4. Condutância estomática $\left(g_{s}\right)$ em folhas de plantas de algodoeiro dos cultivares NuOpal (a, c) e BRS Buriti (b, d) cultivadas em solução nutritiva contendo $0(-\mathrm{Si})$ ou $2 \mathrm{mM}$ de silício $(+\mathrm{Si})$ e não inoculadas $(\mathrm{a}, \mathrm{b})$ ou inoculadas $(\mathrm{c}, \mathrm{d})$ com Ramularia areola; barras em cada ponto representam o desvio padrão da média; médias dos tratamentos -Si e +Si seguidas de asterisco $\left(^{*}\right)$ sáo significativamente diferentes $(\mathrm{p} \leq 0,05)$ pelo teste- $t ; n=10$. 


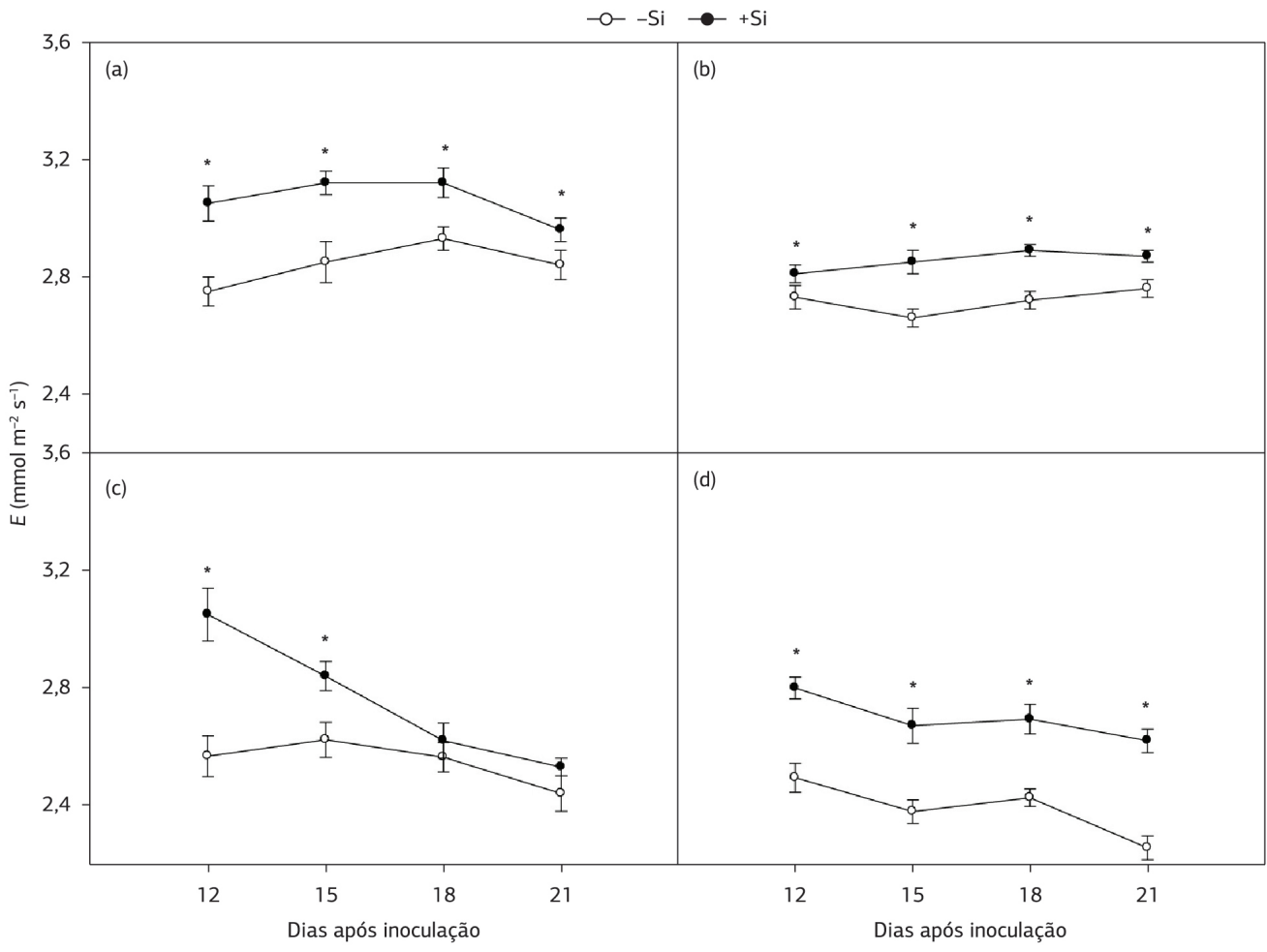

Figura 5. Taxa de transpiração (E) em folhas de plantas de algodoeiro dos cultivares NuOpal (a, c) e BRS Buriti (b, d) cultivadas em soluçáo nutritiva contendo $0(-\mathrm{Si})$ ou $2 \mathrm{mM}$ de silício $(+\mathrm{Si})$ e não inoculadas $(\mathrm{a}, \mathrm{b})$ ou inoculadas $(\mathrm{c}, \mathrm{d})$ com Ramularia areola; barras em cada ponto representam o desvio padráo da média; médias dos tratamentos $-\mathrm{Si}$ e $+\mathrm{Si}$ seguidas de asterisco $\left(^{*}\right)$ sáo significativamente diferentes $(\mathrm{p} \leq 0,05)$ pelo teste- $t ; n=10$.

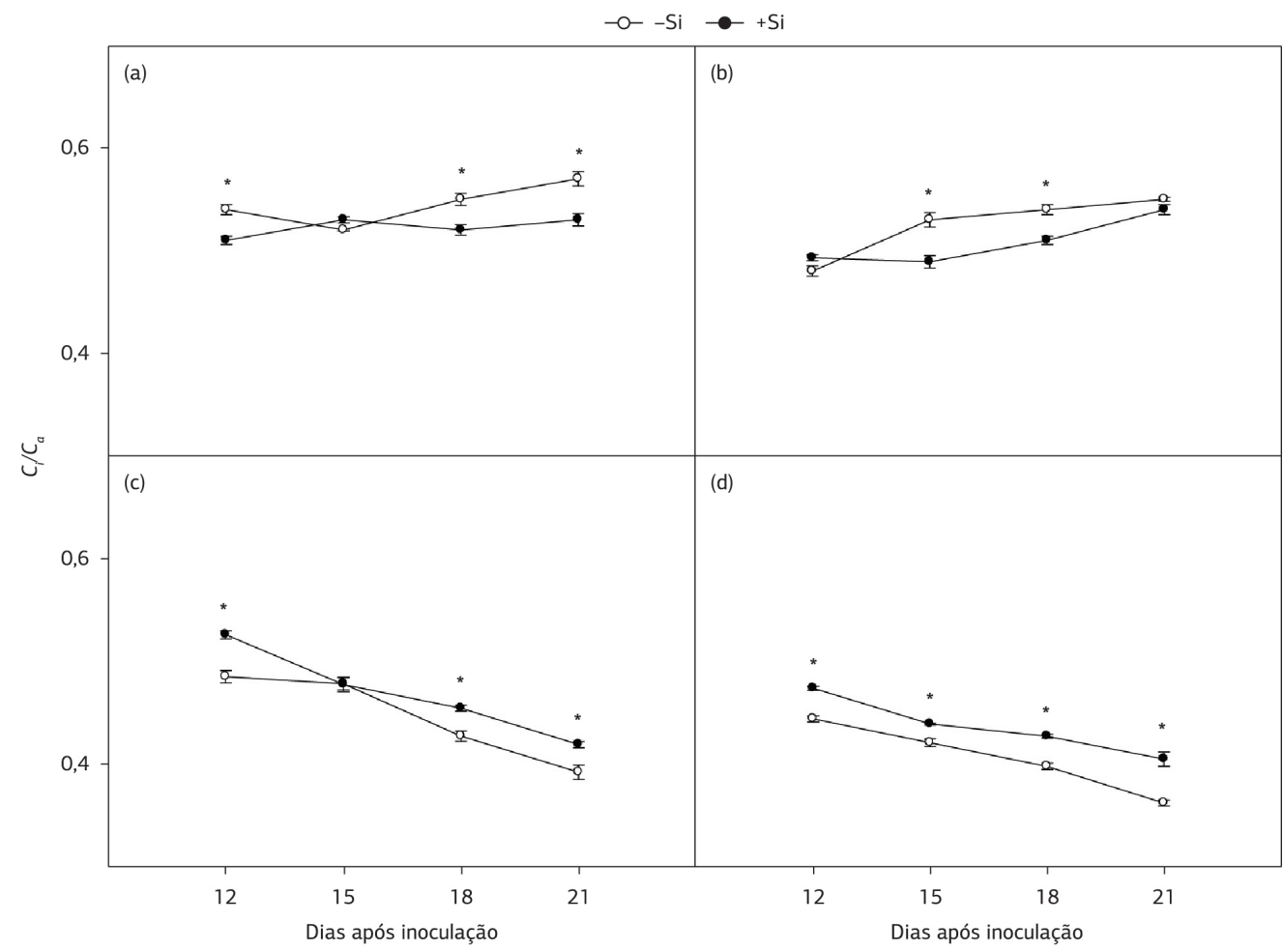

Figura 6. Razão entre a concentração interna e do ambiente de $\mathrm{CO}_{2}\left(C_{i} / C_{a}\right)$ em folhas de plantas de algodoeiro dos cultivares NuOpal (a, c) e BRS Buriti (b, d) cultivadas em solução nutritiva $0(-\mathrm{Si})$ ou $2 \mathrm{mM}$ de silício (+Si) e não inoculadas (a, b) ou inoculadas (c, d) com Ramularia areola; barras em cada ponto representam o desvio padrão da média; médias dos tratamentos $-\mathrm{Si}$ e + Si seguidas de asterisco $\left({ }^{*}\right)$ são significativamente diferentes $(\mathrm{p} \leq 0,05)$ pelo teste- $t, n=10$. 


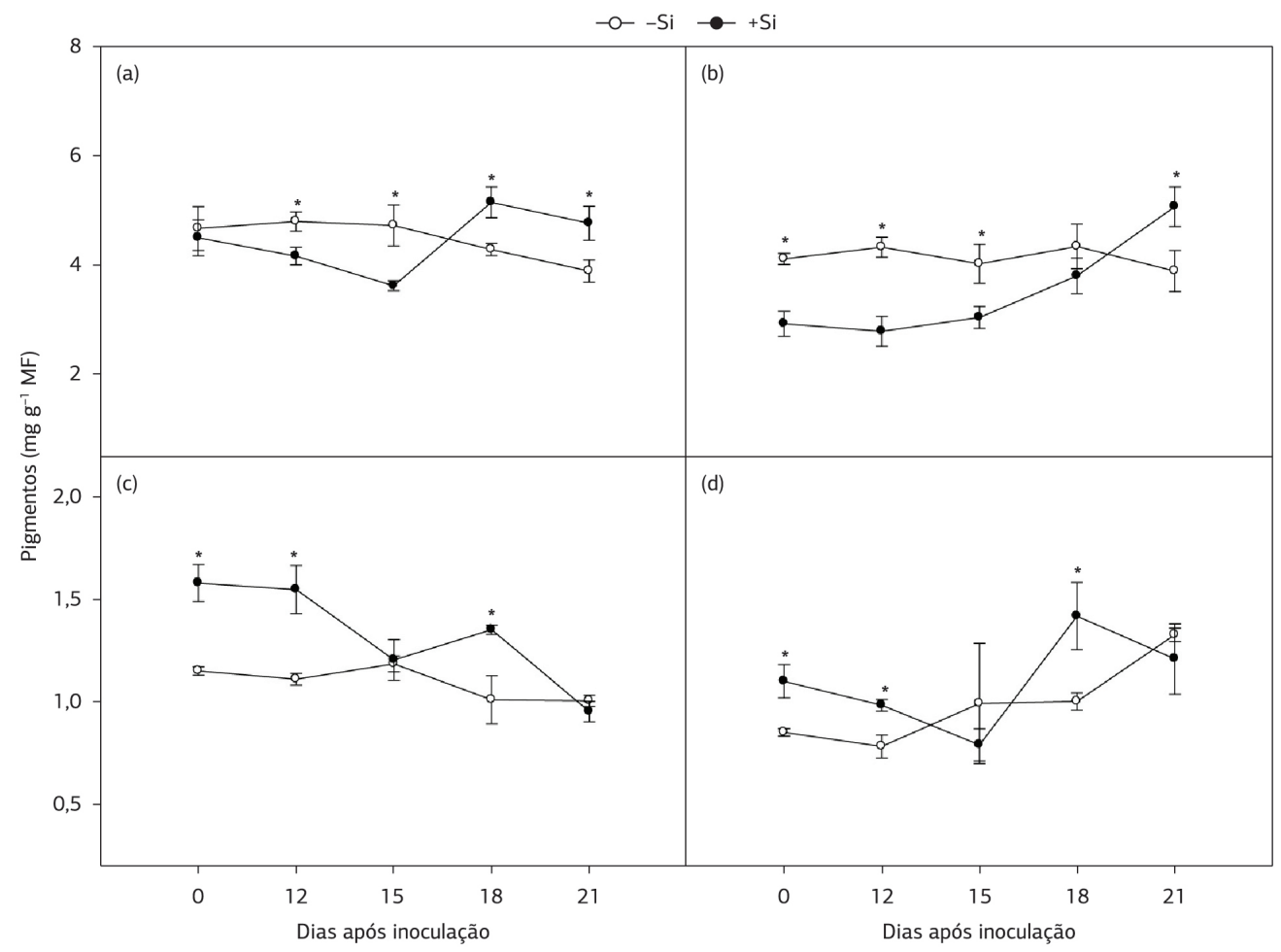

Figura 7. Concentraçóes de clorofila $a$ (a) e de clorofila $b$ (b), razão clorofila al $b$ (c) e concentração de carotenóides (d) em folhas de plantas de algodoeiro do cultivar $\mathrm{NuOpal}$ cultivadas em soluçáo nutritiva contendo $0(-\mathrm{Si})$ ou $2 \mathrm{mM}$ de silício (+Si) e inoculadas com Ramularia areola; barras em cada ponto representam o desvio padrão da média; médias dos tratamentos $-\mathrm{Si} \mathrm{e}+\mathrm{Si}$ seguidas de asterisco $\left({ }^{*}\right)$ são significativamente diferentes $(\mathrm{p} \leq 0,05)$ pelo teste- $t, n=10 ; \mathrm{MF}=$ massa fresca.

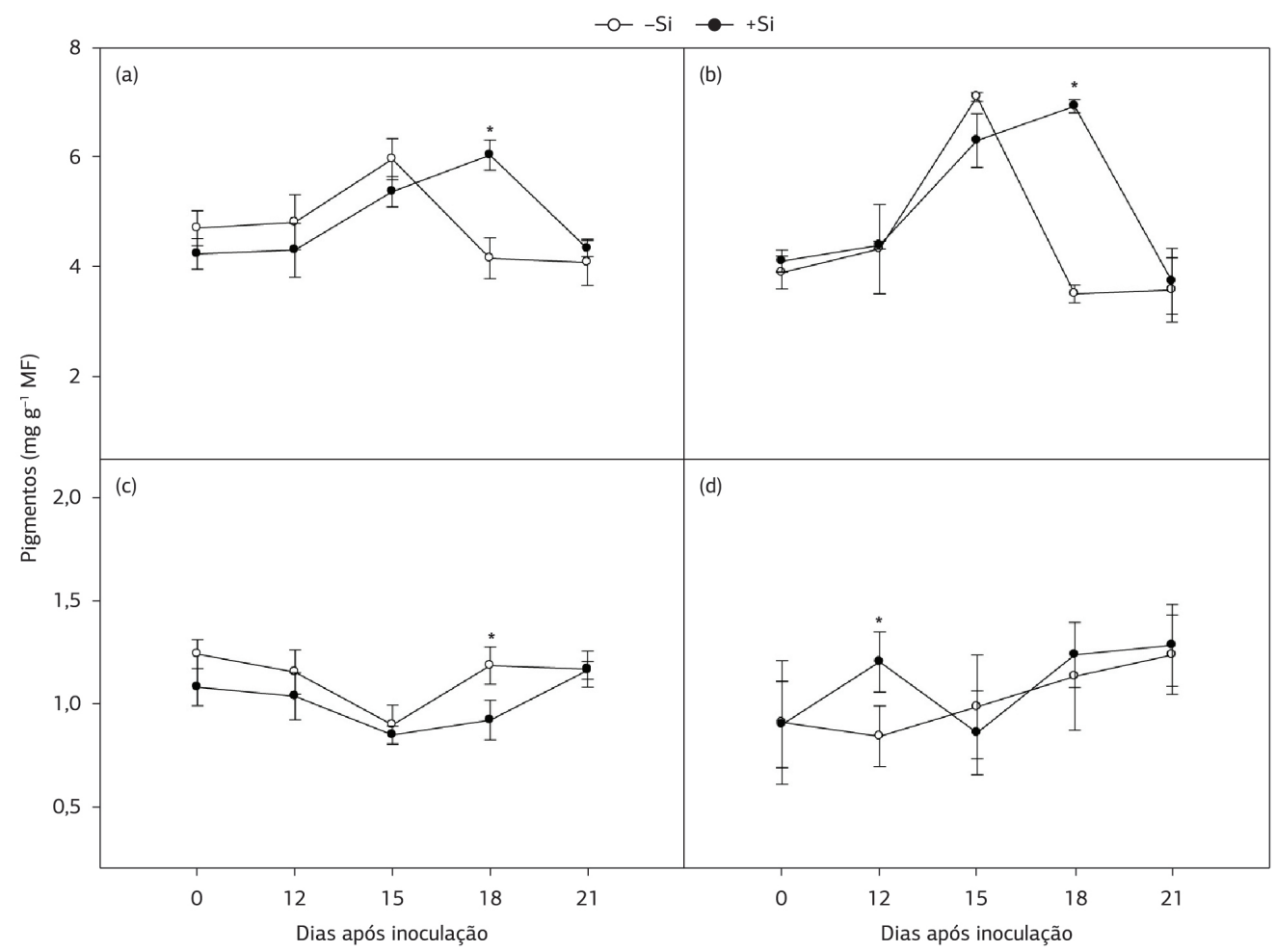

Figura 8. Concentraçôes de clorofila $a$ (a) e de clorofila $b$ (b), razão clorofila $a / b$ (c) e concentração de carotenóides (d) em folhas de plantas de algodoeiro do cultivar BRS Buriti cultivadas em solução nutritiva contendo 0 (-Si) ou 2 mM de silício (+Si) e inoculadas com Ramularia areola; barras em cada ponto representam o desvio padrão da média; médias dos tratamentos $-\mathrm{Si}$ e $+\mathrm{Si}$ seguidas de asterisco $\left({ }^{*}\right)$ são significativamente diferentes $(\mathrm{p} \leq 0,05)$ pelo teste- $t ; n=10 ; \mathrm{MF}=$ massa fresca. 
tenham sido comprometidas, pois o efeito da infecção por $R$. areola nas variáveis relacionadas com as trocas gasosas foi maior nos estádios avançados da infecção.

A redução na transpiração pode estar relacionada com a destruição da cutícula e dos estômatos e com o rompimento do limbo foliar, que afetam diretamente a $g_{\mathrm{s}}$ nas plantas infectadas por $R$. areola. Isso pode ser um reflexo da menor $g_{\mathrm{s}}$, demonstrando que houve uma menor perda de vapor d'água em relação às plantas não supridas com $\mathrm{Si}$. Resultados semelhantes ao do presente estudo foram relatados por HatTori et al. (2005), os quais observaram maior taxa de transpiração e condutância estomática em plantas de sorgo supridas com $\mathrm{Si}$ em relação às plantas não supridas com esse elemento. É possível que o fornecimento de Si tenha colaborado para aumentar a resistência das plantas dos dois cultivares à mancha de ramulária e, simultaneamente, tenha aumentado a fotossíntese. Pode-se inferir que as reduçóes em $A$ provocadas pela infecção por $R$. areola estão relacionadas a limitaçôes no influxo de $\mathrm{CO}_{2}$ nas folhas, mas também com limitaçôes bioquímicas para a fixação de $\mathrm{CO}_{2}$ a nível dos cloroplastos.

A colonização dos tecidos foliares pelo patógeno reduziu a concentração dos pigmentos nas plantas de algodoeiro, principalmente para o cultivar $\mathrm{NuOpal}$. Os carotenóides foram os que sofreram menor alteração. Nas plantas supridas com $\mathrm{Si}$, essas concentraçóes foram maiores apenas nos estádios mais avançados da infecçáo por $R$. areola. Pode-se dizer que o Si afetou as concentraçóes de pigmentos possivelmente devido ao seu efeito como barreira física, reduzindo a colonização dos tecidos por $R$. areola, o que reduziu a AACPMR. Esses resultados diferem dos obtidos por DALLAGNol et al. (2011), os quais mostraram que em estádios mais avançados da infecção por Bipolaris oryzae, em plantas de arroz, ocorreram reduçóes nas concentraçóes de $\mathrm{Cl}_{a}$ e $\mathrm{Cl}_{b}$ devido à intensa colonização dos tecidos foliares pelo patógeno.

Considerando que a degradação da $\mathrm{Cl}_{a}$ não se manifestou sob a forma de lesóes necróticas nas plantas inoculadas e não supridas com $\mathrm{Si}$ do cultivar $\mathrm{NuOpal}$, é possível que tal degradação seja uma estratégia de regulação da absorção e transferência de energia luminosa entre fotossistemas, evitando ou atenuando uma superredução da cadeia fotoquímica da fotossíntese que favorece a produçáo de ERO (MunNÉ-Bosch e Alegre, 1999). Além disso, o fechamento estomático devido à redução na $g_{s}$ interfere na cadeia de transferência de elétrons e reduz a entrada de $\mathrm{CO}_{2}$ nos cloroplastos durante o ciclo de Calvin. Com isso, haverá excesso de NADPH e os elétrons originários da quebra da molécula de água no fotossistema II não terão NADP+ disponível para reduzi-lo. Assim, haverá um forte aumento na quantidade de elétrons que, por sua vez, provocarão foto-oxidação da clorofila nas antenas do fotossistema (BACELAR et al., 2006). Todavia, os resultados do presente trabalho indicam que as plantas de algodoeiro supridas com Si foram pouco eficientes na manutenção das concentraçóes de $\mathrm{Cl}_{a}, \mathrm{Cl}_{b}$ e de carotenóides, principalmente as do cultivar BRS Buriti.

O fornecimento de Si contribuiu para aumentar a atividade das enzimas SOD, APX e GR nas plantas de algodoeiro infectadas por $R$ areola, impactando negativamente o progresso da mancha de ramulária e indicando um possível envolvimento do Si na potencialização da resistência do algodoeiro à $R$. areola. Resultados semelhantes demonstraram os efeitos benéficos do Si na redução da intensidade de doenças em várias culturas economicamente importantes (Datnoff et al., 2007). A atividade das enzimas antioxidantes SOD, APX e CAT é geralmente incrementada para promover melhor eliminaçáo das ERO e uma maior proteçáo celular contra danos oxidativos (AsAda, 1999). Para evitar esses danos oxidativos, a atividade da APX náo deve ser apenas alta mas suficientemente equilibrada, de forma que possa eliminar o $\mathrm{H}_{2} \mathrm{O}_{2}$ gerado pela açáo da SOD (AsAdA, 1999). No presente trabalho, a maior atividade da SOD, que potencialmente acarreta maior produçáo de $\mathrm{H}_{2} \mathrm{O}_{2}$, foi acompanhada por incremento nas atividades da APX e GR, ainda que a atividade da CAT não tenha sido alterada pelo $\mathrm{Si}$. Tomados em conjunto, esses resultados sugerem um papel de destaque das enzimas APX e GR na redução da concentração de $\mathrm{H}_{2} \mathrm{O}_{2}$. Isso explicaria, pelo menos em parte, as reduçóes no extravazamento de eletrólitos e a menor peroxidaçáo lipídica. De qualquer modo, como as atividades da SOD e da APX foram maiores nas plantas do cultivar BRS Buriti supridas com $\mathrm{Si}$, pode-se inferir que esse cultivar, por ser considerado moderadamente resistente, apresenta outros mecanismos de defesa que contribuíram para a redução de $\mathrm{H}_{2} \mathrm{O}_{2}$, MDA e EE. ZHu et al. (2004) relataram aumento nas atividades da SOD, APX, GR, com exceção da CAT, em plantas de pepino supridas com Si e mantidas sob estresse salino. Os resultados obtidos neste trabalho para o $\mathrm{H}_{2} \mathrm{O}_{2}$ reforçam a hipótese de que o Si pode potencializar o aumento das atividades das enzimas do metabolismo antioxidativo de plantas sob condiçóes de estresse.

Altas concentrações de MDA produzidos durante a peroxidação de lipídeos são forte indicador dos danos celulares causados às membranas, o que resulta em aumento na magnitude do EE (Liang et al., 2003). A menor AACPMR nas plantas supridas com Si indica, indiretamente, uma menor colonização do fungo nos tecidos foliares, o que é associado com a menor concentração de $\mathrm{H}_{2} \mathrm{O}_{2}$, de MDA e de EE. Resultados semelhantes foram observados por LiANG et al. (2003), os quais demonstraram que a concentração de MDA e EE foram menores nas plantas de cevada supridas com Si sob condiçóes de estresse. No presente trabalho, as concentraçôes de MDA evidenciaram claramente que as plantas de algodoeiro sofreram danos oxidativos nos lipídios da membrana, com efeitos na sua permeabilidade, principalmente nas plantas do cultivar $\mathrm{NuOpal}$ náo supridas com Si, considerada suscetível ao patógeno. Efeitos benéficos do Si atuando na integridade da membrana plasmática já 
foram relatados em plantas de pepino sob condiçóes de estresse salino (ZHU et al., 2004), porém a magnitude dos danos oxidativos difere entre espécies ou genótipos de plantas em resposta à intensidade e duração do estresse (SGHERRI et al., 2000).

O aumento da atividade da LOX foi constatado nas plantas dos dois cultivares supridas com $\mathrm{Si}$ até os 12 dai, indicando sua participação na resposta da planta de algodoeiro ao ataque do patógeno. Tem sido relatado que a magnitude da atividade de LOX no tecido vegetal pode variar, como resposta fisiológica da planta a diferentes tipos de estresse (Silva et al., 2001). Esses autores observaram ainda que a LOX aumentou em plantas de soja infectadas por Diaphorte phaseolorum f.sp. meridionalis.

\section{CONCLUSÃO}

O suprimento de $\mathrm{Si}$ afetou a fisiologia das plantas de algodoeiro durante o processo infeccioso de $R$. areola, auxiliando na manutenção da integridade da membrana plasmática e numa melhor capacidade fotossintética.

Nas plantas supridas com $\mathrm{Si}$, o sistema antioxidativo, especificamente com a ação das enzimas SOD, APX e GR, foi mais eficiente, colaborando para uma maior resistência das plantas de algodoeiro à infecção por $R$. areola, principalmente nas plantas do cultivar BRS Buriti, considerado moderadamente resistente. Porém as plantas do cultivar $\mathrm{NuOpal}$, mesmo sendo considerado suscetível a $R$. areola, responderam eficientemente à aplicação do Si em termos de redução dos sintomas da ramulária.

\section{AGRADECIMENTOS}

À Fundaçáo de Amparo à Pesquisa do Estado de Minas Gerais (FAPEMIG), pelo recurso financeiro (Processo APQ01159-09). Ao CNPq, pela bolsa de doutorado concedida à dra. C. R. S. Curvêlo e pelas bolsas de produtividade em pesquisa dos professores F. A. Rodrigues, P. G. Berger e F. M. DaMatta.

\section{REFERÊNCIAS}

ALSCHER, R.G.; ERTURK, N.; HEATH, I.S. Role of superoxide dismutses (SOD) in controlling oxidative stress in plants. Journal of Experimental Botany, v.53, p.1331-1341, 2002. PMid:11997379. http://dx.doi.org/10.1093/jexbot/53.372.1331

ANDRADE, P.M.C.; CASSETARI NETO, D.; MACHADO, A.Q. Controle químico de doenças em algodoeiro no Mato Grosso. Fitopatologia Brasileira, v.24, p.262-265, 1999.
AQUINO, L.A.; BERGER, P.G.; RODRIGUES, F.A.; ZAMBOLIM, L.; HERNANDEZ, J.F.R.; MIRANDA, L.M. Elaboração e validação de escala diagramática para quantificação da mancha de ramulária do algodoeiro. Summa Phytopathologica, v.34, p.361-363, 2008. http:// dx.doi.org/10.1590/S0100-54052008000400012

ASADA, K. The water-water cycle in cloroplasts: Scavenging of Active Oxygen and Dissipation of Excess Photons. Annual Review of Plant Physiology and Plant Molecular Biology, v.50, p.601-639, 1999. PMid:15012221. http://dx.doi.org/10.1146/annurev.arplant.50.1.601

AXELROD, B.; CHEESBROUGH, T.M.; LAAKSO, S. Lipoxygenases from soybeans. In: LOWENSTEIN, J.M. (Ed.). Methods in Enzymology. New York: Academic Press, 1981. p.441-451. PMid:6258719.

BACELAR, E.A.; SANTOS, D.L.; MOUTINHO-PEREIRA, J.; GONÇALVES, B.C.; FERREIRA, H.F.; GONÇALVES, B.C.; FERREIRA, H.F.; CORREIA, C.M. Immediate responses and adaptative strategies of three olive cultivars under contrasting water availability regimes: changes on structure and chemical composition of foliage and oxidative damage. Plant Science, v.170, p.596-605, 2006. http://dx.doi.org/10.1016/j.plantsci.2005.10.014

BERGER, S.; SINHA, A.K.; ROITSCH, T. Plant physiology meets phytopathology: plant primary metabolism and plant-pathogen interactions. Journal of Experimental Botany, v.58, p.4019-4026, 2007. PMid:18182420. http://dx.doi.org/10.1093/jxb/erm298

BOLTON, M.D. Primary metabolism and plant defense fuel for the fire. Molecular Plant-Microbe Interactions, p.487-97, 2009. PMid:19348567. http://dx.doi.org/10.1094/MPMI-22-5-0487

BRADFORD, M.M. A rapid and sensitive method for the quantitation of microgram quantities of protein utilizing the principle of proteindye binding. Analytical Biochemistry, v.72, p.248-254, 1976. http:// dx.doi.org/10.1016/0003-2697(76)90527-3

CAKMAK, I., HORST, W. J. Effect of aluminum on lipid peroxidation, superoxide dismutase, catalase, and peroxidase activities on root tips of soybean (Glycine max). Physiologia Plantarum, v.83, p.463-468, 1991. http://dx.doi.org/10.1111/j.1399-3054.1991.tb00121.x

CAKMAK, I.; STRBAC, D; MARSCHNER, H. Activities of hydrogen peroxides scavenging enzymes in germinating wheat seeds, Journal of Experimental Botany, v.44, p.127-132, 1993. http://dx.doi. org/10.1093/jxb/44.1.127

CARLBERG, I.; MANNERVIK, B. Glutathione reductase. In: DOUCE, R.; PACKER, L. (Ed.). Methods in Enzymology. 1985. p.484-490. PMid:3003504.

DALLAGNOL, L.J.; RODRIGUES, F.A.; MARTINS, S.C.V.; CAVATTE, P.C.; DAMATTA, F.M. Alterations on Rice leaf physiology during infection by Bipolaris oryzae. Australasian Plant Pathology, v.40, p.360-365, 2011. http://dx.doi.org/10.1007/s13313-011-0048-8

DATNOFF, L.E.; RODRIGUES, F.A.; SEEBOLD, K.W. Silicon and Plant Disease. In: DATNOFF, L.E.; ELMER, W.H.; HUBER, D.M. (Ed.). Mineral Nutrition and Plant Disease. St Paul: APS Press, 2007. p.233-246.

EPSTEIN, E. Silicon. Annual Review of Plant Physiology and Plant Molecular Biology, v.50, p.641-664, 1994. PMid:15012222. http:// dx.doi.org/10.1146/annurev.arplant.50.1.641 
FOYER, C.H.; HALLIWELL, B. The presence of glutathione and glutathione reductase in chloroplasts: a proposed role in ascorbic acid metabolism. Planta, v.133, p.21-25, 1976. http://dx.doi.org/10.1007/ BF00386001

FREIRE, E.C. História do algodoeiro no Cerrado. In: FREIRE, E.C. (Ed.). Algodão no Cerrado do Brasil. Brasília, 2011. p.23-61. PMid:22171824.

GAY, C.; GEBICKI, J.M.A. Critical evalution of the effect of sorbitol on the ferricxylenol orange hydroperoxide assay. Analytical Biochemistry, v.284, p.217-220, 2000. PMid:10964403. http:// dx.doi.org/10.1006/abio.2000.4696

GIANNOPOLITIS, C.N.; RIES, S.K. Superoxide dismutases. I. Occurrence in higher plants. Plant Physiology, v.59, p.309-314, 1977. PMid:16659839 PMCid:PMC542387. http://dx.doi.org/10.1104/ pp.59.2.309

HATTORI, T.; INANAGA, S.; ARAKI, H.P.; MORITA, S.; LUXOVA, M.; LUX, A. Application of silicon enhanced drought tolerance in Sorghum bicolor. Physiologia Plantarum, v.123, p.459-466, 2005. http://dx.doi.org/10.1111/j.1399-3054.2005.00481.x

HAVIR, E.A.; MCHALE, N.A. Biochemical and developmental characterization of multiple forms of catalase in tobacco leaves. Plant Physiology, v.84, p.450-455. 1987. PMid:16665461 PMCid:PMC1056601. http://dx.doi.org/10.1104/pp.84.2.450

HOAGLAND, D.R.; ARNON, D.I. The water culture method for growing plants without soil. California Agricultural Experiment Station, Cir. 32, 1950.

KIM, S.G., KIM, K.W., PARK, E.W., CHOI, D. Silicon-induced cell wall fortification of rice leaves, a possible cellular mechanism of enhanced host resistance to blast. Phytopathology, v.92, p.1095-1103, 2002. PMid:18944220. http://dx.doi.org/10.1094/PHYTO.2002.92.10.1095

KORNDÖRFER, G.H.; PEREIRA, H.S.; NOLLA, A.O. Análise de silício: solo, planta e fertilizante. Uberlândia: Grupo de Pesquisa em Silício, ICIAG, Universidade Federal de Uberlândia, 2004. 34p.

KUO, M.C.; KAO, C.H. Aluminum effects on lipid peroxidation and antioxidative enzyme activities in rice leaves. Biologia Plantarum, v.46, p.149-152, 2003. http://dx.doi.org/10.1023/A:1022356322373

LIANG, Y.C.; CHEN, Q.; LIU, Q.; ZHANG, W.H.; DING, R.X. Exogenous silicon ( $\mathrm{Si}$ ) increases antioxidant enzyme activity and reduces lipid peroxidation in roots of salt-stressed barley (Hordeum vulgare L.). Journal of Plant Physiology, v.160, p.1157-1164, 2003. PMid:14610884. http://dx.doi.org/10.1078/0176-1617-01065

LICHTENTHALER, H.K. Chlorophylls and carotenoids, the pigments of photosynthetic biomembranes. In: DOUCE, R.; PACKER, L. (Ed.). Methods in Enzimology. 1987. v.148, p.350-381.

LIMA, A.L.S.; DAMATTA, F.M.; PINHEIRO, H.; TOTOLA, M.R.; LOUREIRO, M.E. Photochemical responses and oxidative stress in two clones of Coffea canephora under water deficit conditions.
Environmental and Experimental Botany, v.47, p.239-247. 2002. http://dx.doi.org/10.1016/S0098-8472(01)00130-7

MA, J.F. Role of silicon in enhancing the resistance of plants to biotic and abiotic stresses. Soil Science and Plant Nutrition, v.50, p.11-18, 2004. http://dx.doi.org/10.1080/00380768.2004.10408447

MA, J.F.; TAKAHASHI, E. Soil, fertilizer and plant silicon research in Japan. Elsevier Science, 2002. 274p.

MARUR, C.J.; RUANO, O. A reference system of determination of cotton plant development. Revista de Oleaginosas e Fibrosas, v.5, p.313-317, 2001.

MUNNÉ-BOSCH, S.; ALEGRE, L. Role of dew on the recovery of water-stressed Melissa officinalis L. plants. Journal of Plant Physiology, v.154, p.759-766, 1999. http://dx.doi.org/10.1016/ S0176-1617(99)80255-7

NAKANO, Y.; ASADA, K. Hydrogen peroxide is scavenged by ascorbate- specific peroxidase in spinach chloroplasts, Plant and Cell Physiology, v.22, p.867-880, 1981.

PEIXOTO, P.H.P.; CAMBRAIA, J.; SANTANA, R.; MOSQUIM, P.R.; MOREIRA, M.A. Aluminum effects on lipid peroxidation and on the activities of enzymes of oxidative metabolism in sorghum. Brazilian Journal of Plant Physiology, v.11, p.137-143, 1999.

SGHERRI, C.L.M.; MAFFEI, M.; NAVARI-IZZO, F. Antioxidative enzymes in wheat subjected to increasing water deficit and rewatering. Journal of Plant Physiology, v.157, p.273-279, 2000. http://dx.doi. org/10.1016/S0176-1617(00)80048-6

SHANER, G.; FINNEY, R.E. The effect of nitrogen fertilization on the expression of slow-mildewing resistance in Knox wheat. Phytopathology, v.67, p.1051-1056, 1977. http://dx.doi.org/10.1094/Phyto-67-1051

SILVA, M.D.; OLIVEIRA, M.G.A.; LANNA, A.C.; PIRES, C.V.; PIOVESAN, N.D.; JOSÉ, I.C.; BATISTA, R.B.; BARROS, E.G.; MOREIRA, M.A. Caracterização da via das lipoxigenases em plantas de soja resistentes e susceptíveis a Diaphorte phaseolorum f.sp. Meridionalis, agente causal do cancro-da-haste. Revista Brasileira de Fisiologia Vegetal, v.13, p.316-328, 2001. http://dx.doi.org/10.1590/ S0103-31312001000300007

SISTEMA DE ANÁLISES ESTATÍSTICAS E GENÉTICAS - SAEG. versão 9.1. Viçosa: UFV, 2007.

SUASSUNA, N.D.; COUTINHO, W.M. Manejo das principais doenças do algodoeiro no cerrado brasileiro. In: FREIRE, E.C. (Ed.). Algodão no Cerrado do Brasil. Brasília, 2011. p.479-521.

YAN, B.; DAI, Q.; LIU, X.; HUANG, S.; WANG, Z. Floodinginduced membrane damage, lipid oxidation and activated oxygen generation in corn leaves. Plant and Soil, v.179, p.261-268, 1996. http://dx.doi.org/10.1007/BF00009336

ZHU, Z.; WEI, G.; LI, J.; QIAN, Q.; YU, J. Silicon alleviates salt stress and increases antioxidant enzymes activity in leaves of salt-stressed cucumber (Cucumis sativus L.). Plant Science, v. 167, p.527-533, 2004. http://dx.doi.org/10.1016/j.plantsci.2004.04.020 